\title{
Análisis de contenidos entre estudios de Bachiller Artístico y Grado en Bellas Artes
}

\author{
Concepción Alonso VAldivieso \\ Universidad de Granada \\ alonsov@ugr.es
}

\begin{abstract}
Resumen:
Para iniciar estudios de Grado en Bellas Artes no se requiere cursar previamente estudios de Bachillerato Artístico. Esta situación afecta directamente a nuestra titulación ya que muchas asignaturas parten de un nivel de conocimiento poco elevado y en algunas ocasiones los contenidos de las materias de Bachillerato y Grado son redundantes. Hemos analizado ambos planes de estudio y propuesto un punto de partida en el Grado que corresponda a unos estudios universitarios, asumiendo que los alumnos que no lo alcancen deben comprometerse a adquirirlo por su cuenta como ocurre en otras titulaciones.
\end{abstract}

Palabras clave: Educación; Bellas Artes; Competencias artísticas; Mejora de aprendizaje

\section{Content analysis between High School and the Degree in Fine Arts}

\begin{abstract}
:
To initiate studies in a Fine Arts degree it is not required prior to study high school artistic. This situation directly affects our degree as many courses start from a low level of knowledge and sometimes the content of subjects in high school and degree are redundant. We have analyzed both curriculums and have proposed a starting point in degree that corresponds to university studies, assuming that students who do not have this level must commit to acquire it on their own as in other degrees.
\end{abstract}

Keywords: Education; Fine Art; Artistic skills; Learning improvement

\section{Referencia normalizada:}

Alonso Valdivieso, C. (2014): Análisis de contenidos entre estudios de Bachiller Artístico y Grado en Bellas. Historia y Comunicación Social. Vol. 19. Núm. Especial Marzo. Págs. 73-81.

Sumario: 1. Introducción, 2. Metodología, 3. Contraste entre planes de estudios 3.1. Dibujo Artístico I y II (Bachiller), 3.2 Dibujo I Lenguajes y Materiales - Principios Básicos del Dibujo (BBAA) 3.3. Técnicas de Expresión Grafico Plásticas (Bachiller) 3.4. Pintura I Lenguajes y Materiales - Principios Básicos de la Pintura (BBAA) 3.5. Dibujo Técnico I y II (Bachiller) 3.6. Sistemas de Análisis de la Forma y la Representación (BBAA) 3.7. Volumen (Bachiller) 3.8. Escultura I Lenguajes y Materiales - Principios Básicos de la Escultura (BBAA) 3.9. Historia del Arte (Bachiller) y Teoría e Historia del Arte (BBAA) 3.10. Cultura Audiovisual (Bachiller) 3.11. Audiovisuales (BBAA) 4. Nuestra propuesta, 5. Conclusiones. 


\section{Introducción}

Los alumnos que inician estudios de Grado en Bellas Artes no tienen obligación de haber adquirido ningún tipo de conocimiento previo en el campo del arte. No es obligatorio haber estudiado previamente Bachillerato Artístico y tampoco existe ya una prueba de acceso que sitúe en un nivel moderado el inicio a estos estudios. En cambio, la mayoría de titulaciones si exige unos estudios previos para poder acceder a determinados Grados.

Observamos en cada curso escolar un enorme desnivel entre los alumnos que proceden de estudios de Bachillerato y los que han cursado otros distintos. Como profesores se nos hace difícil encontrar un punto intermedio en el que todos los alumnos estén cómodos, tal vez para unos los contenidos ya han sido aprendidos y quizá estén lejos del alcance de otros.

En un intento de solventar este problema nos proponemos observar cuáles con los contenidos impartidos en las enseñanzas de Bachillerato Artístico y los impartidas en primer curso de Grado en Bellas Artes con la intención de dar como aprendidos los contenidos de Bachiller y partir desde el punto en que se quedan éstos para iniciar los nuestros. Queremos en este caso apoyar a los alumnos que ya han estudiado Bachillerato Artístico para que puedan seguir avanzando en sus carreras y solicitar a los alumnos que no lo hayan hecho que adquieran por su cuenta los conocimientos mínimos para poder seguir las asignaturas, lo que ocurre en la mayoría de estudios universitarios.

\section{Metodología}

En primer lugar debíamos conocer los contenidos y competencias de aquellas asignaturas troncales y optativas ligadas a las materias de Grado en BBAA para poder establecer un punto de partida en nuestros estudios universitarios. Hemos consultado la página oficial de la Junta de Andalucía en la que está publicado el Decreto $416 / 2008^{1}$, de 22 de julio en el que se establece la ordenación y las enseñanzas correspondientes al bachillerato en Andalucía.

Las asignaturas analizadas en nuestra investigación han sido:

- Dibujo Artístico

- Dibujo Técnico

- Historia del Arte

- Cultura Audiovisual

1 [09-05-2013] http://www.juntadeandalucia.es/educacion/portal/com/bin/Contenidos/OEE/ordenacion/Orden_Curriculo_Bachillerato/1220265787283_orden_bachillerato.pdf 
- Técnicas de Expresión Grafico Plásticas

- Volumen.

Los estudios de Bachillerato se dividen en dos cursos. A partir del segundo los alumnos pueden elegir entre dos ramas distintas; Artes Plásticas o Artes Aplicadas y Diseño. Algunas de las asignaturas impartidas en cada especialidad son compartidas pero otras asignaturas obligatorias son diferentes. También cursarán dos materias optativas que dependerán del centro de estudios pues no todos ofertan las mismas.

Una vez analizados las planes de estudio de Bachillerato Artístico los hemos contrastado con las guías docentes de las asignaturas de primer curso de Grado, a las que se pueden acceder a través de la página web de la facultad de Bellas Artes, donde son revisadas y actualizadas cada año. Así hemos podido comprobar si existen materias que tengan contenidos redundantes o sí por el contrario han quedado lagunas entre unas y otras. Las asignaturas analizadas han sido las siguientes:

- Dibujo I; Lenguajes y materiales

- Principios básicos del dibujo

- Escultura I; Lenguajes y materiales

- Principios básicos de la escultura

- Pintura I; Lenguajes y materiales

- Principios básicos de la pintura

- Sistemas de análisis de la forma y la representación

- Teoría e historia del arte

- Audiovisuales

Dibujo I; Lenguajes y materiales es una asignatura semestral que se imparte al inicio del curso y se conecta con Principios Básicos del Dibujo, de modo que ésta es una continuación de la anterior. A la hora de comprarla con la asignatura de Dibujo Artístico de Bachiller la hemos tratado como una sola. Del mismo modo ocurre con Escultura y Pintura.

\section{Contraste entre planes de estudio}

Como ya hemos mencionado nuestra intención ha sido estudiar el plan de estudios de primer curso de Grado en BBAA, en cambio a la hora de analizar el plan de estudios de Bachiller lo hemos hecho de los dos años ya que no interesa el contenido completo de este periodo ya que existen asignaturas que se dan en el primer año y no en el segundo, como por ejemplo Volumen. 


\subsection{Dibujo artístico y II (Bachiller)}

La primera se ocupa de iniciar al alumno en el uso de materiales y procedimientos. Empiezan a hablarse de conceptos como la forma, el claroscuro, la línea e incluso la perspectiva. La segunda, siendo una continuación a la primera, ahonda en nuevos conceptos sobre composición trabajando el boceto, el encuadre y el encaje. Se combinan estas lecciones con prácticas con clases teóricas en las que se habla sobre la importancia de la composición en la historia del arte.

3.2. Dibujo I Llenguajes y materuales. Principios básicos del dibujo (Grado Bellas Artes)

Partiendo de la creencia de que el alumno no tienen ningún conocimiento previo, Dibujo I establece su inicio en la introducción de técnicas, materiales, utensilios de dibujo. Para poner en práctica estas nociones se representa el entorno natural y la figura humana. Principios Básicos del Dibujo en continuación con Dibujo I incide en conceptos básicos como el punto, la línea, el plano, la mancha a través de prácticas consistentes en realizar grafismos como se ha venido haciendo en desde la infancia. También se centra en el encaje, la proporción, el movimiento y el espacio.

Tanto en las asignaturas de Bachillerato como en las de Grado se observan contenidos repetidos partiendo ambos estudios de un nivel básico. Las asignaturas de Dibujo en el Grado retornan a conceptos como la línea, el punto o la mancha. Las ejercicios con los que se inician los alumnos son prácticas sobre contorno ciego, líneas geodésicas o creación de texturas antes de empezar con la representación de modelos vivos.

\subsection{Técnicas de expresión gráfico plásticas (Bachiller)}

Esta asignatura optativa impartida en el segundo curso de Bachiller tendría su correspondencia con las asignaturas de pintura en el Grado. En ella se dan la primeras nociones sobre técnicas artísticas, útiles de dibujo, pintura, grabado o estampación y cómo se procede antes las diferentes técnicas según los materiales.

\subsection{Pintura I Llenguajes y materiales. Principios básicos de la pintura (Grado BBAA)}

Pintura I es una iniciación a las técnicas pictóricas; acuarelas, acrílicos, óleos entre otras. También se encarga de estudiar cuál es el proceso creativo de determinados artistas haciendo un repaso por los movimientos artísticos. Principios Básicos de la Pintura estudia la teoría del color y su aplicación creativa. En ambas asignaturas se realizan prácticas de realización de bodegones con distintos materiales pictóricos en soportes y materiales para técnicas al agua.

Desde la educación primaria se les enseña a los alumnos la teoría del color. Probablemente aún queden conceptos por aprender pero la realización de prácticas sobre el círculo cromático, colores complementarios o ejercicios sobre colores fríos y cálidos como se hace en Principios Básicos de la Pintura no son de nivel universitario. 


\subsection{Dibujo técnico I y II (Bachiller)}

Ambas asignaturas hacen un recorrido por distintos sistemas de representación. La primera se inicia en la perspectiva caballera, axonométrica y el sistema diédrico. Desde este último se inician los estudios en la asignatura de segundo curso ampliando los conocimientos adquiridos y entrenando a los alumnos en el uso de herramientas informáticas como el software Autocad, un programa de diseño asistido por ordenador que permite dibujar tanto en $2 \mathrm{D}$ como $3 \mathrm{D}$.

\subsection{Sistermas de análisis de la forma y la representación (Gado BBAA)}

De nuevo se vuelven a estudiar los sistemas de representación mencionados anteriormente. Se hace un análisis de las formas Bi y Tridimensionales a través del sistema diédrico, axonométrico y proyección cónica.

Ambas asignaturas tienen muchos contenidos comunes. En Bachillerato estos contenidos son llevados a la práctica a través de la realización de distintas láminas en las que se proyectan figuras geométricas. En los estudios de Grado se repite el estudio de algunos sistemas de representación aunque su estudio es más profundo, además tiene un aplicación práctica en el diseño de modelos arquitectónicos reales y diseños industriales. También se realiza dibujo arquitectónico al natural aplicando la perspectiva a mano alzada. Si bien carece de enseñanzas sobre software específico para dibujo técnico.

\subsection{Volumen (Bachiller)}

A través de técnicas escultóricas como el modelado en barro se hace un estudio de la forma tridimensional desde un punto de vista creativo y expresivo. Es una toma de contacto con la técnica del barro y su manipulación, estructuras, tratamiento y pátinas de acabado.

3.8 Escultura I lenguajes y materiales. Principios básicos de la escultura (Grado BBAA)

Se introduce al alumnado en los principales materiales escultóricos y tratamientos. Principios Básicos de la Escultura estudia conceptos que profundizan más en la construcción de estructuras, en la materia, el espacio o la luz así como lenguajes escultóricos.

Tanto en los estudios de Bachiller como en los de Grado los alumnos comienzan a trabajar el barro. En la primera se trata de prácticas de pequeño tamaño que inician al alumno en el tratamiento de la materia y la tridimensionalidad mediante la realización de relieves y figuras exentas. En la segunda aunque también se trata la misma técnica empieza a hacerse desde un punto de vista artístico, es decir, se pretenden que las obras empiecen a tener un significado más allá de lo estético. Por tanto no sólo mejoran su técnica sino que empiezan a argumentar su trabajo. 


\subsection{Historia del arte (Bachiller) y teoría e historia del arte (Grado BBAA)}

Ambas asignaturas tienen un contenido prácticamente idéntico, se trata de recorrido a lo largo de la historia para estudiar la evolución del arte desde la prehistoria a la actualidad.

Para superar las asignaturas el alumnos deberá realizar un examen consistente en el reconocimiento y análisis de una obra de arte.

\subsection{Cultura audiovisual (Bachiller)}

Es una asignatura de segundo curso que puede escogerse como optativa. En ella se estudian modos de imagen fija, desde la fotografía, imágenes CGI, hasta cómic. Y además imágenes en movimiento, cine, animación y publicidad.

\subsection{Audiovisuales (Grado BBAA)}

En Audiovisuales se inicia el curso haciendo un repaso sobre todos los acontecimientos que hicieron posible la invención del cine, desde los primeros juguetes ópticos hasta su desarrollo final. Se estudia el lenguaje fílmico y se prepara al alumno para la creación de un proyecto audiovisual.

La asignatura Cultura Audiovisual hace un estudio de la imagen fija y en movimiento, introduce ya algunos conceptos sobre lenguaje audiovisual, conceptos que la asignatura de Grado retoma y profundiza. Un aspecto que resulta esencial conocer para que los alumnos puedan realizar sus proyectos audiovisuales de un modo planificado y profesional.

\section{Nuestra propuesta}

Adaptar las antiguas licenciaturas a los nuevos créditos europeos ha supuesto una enorme modificación en los planes de estudios. Desde que esto ocurrió no ha transcurrido mucho tiempo y resulta normal que en ciertos aspectos aún se pueda mejorar. Por ello, a través de este análisis pretendemos mejorar el sistema desde nuestra pequeña parcela intentando solventar un problema con el que nos topamos a diario como profesores universitarios.

Acabamos de comprobar que algunas asignaturas con afinidad temática tienen contenidos solapados. Algunas de ellas sí parten de lo estudiado en Bachiller y otras resultan muy redundantes.

Creemos necesario aumentar el nivel de partida de muchas asignaturas impartidas en primer curso ya que se hace absurdo que unos estudios universitarios tengan un nivel de bachillerato. Lo idóneo sería que todos los alumnos que ingresan en Bellas Artes hubieran estudiado previamente el Bachillerato Artístico pero si no lo hicieron 
es bajo su responsabilidad. Al igual que un alumno que estudia Bachillerato Artístico no puede entrar a estudiar Medicina, en cambio en nuestro caso se aceptan alumnos de cualquier procedencia.

El profesorado se enfrenta a una difícil tarea ya que en un mismo aula encuentra alumnos con conocimientos básicos y otros que no saben sujetar un carboncillo. Estos últimos acaban retrasando el aprendizaje de los primeros ya que el profesor se ve obligado a establecer un punto de partida accesible para todos. El único modo de terminar con este problema es asumiendo que el alumno debe preocuparse por sí mismo de adquirir esos conocimientos básicos para poder desarrollar el curso con normalidad.

Como hemos observado, las asignaturas troncales de cada rama de Grado (dibujo, pintura y escultura) parten de la creencia de que el alumno no sabe absolutamente nada de ninguna materia. Todas coinciden en sus inicios en familiarizar a los alumnos con determinados soportes y materiales que ya se han visto en Bachillerato. Las primeras nociones que reciben en torno al dibujo o la pintura tratan sobre la línea, la mancha o el claroscuro mediante la realización de bodegones cuando lo verdaderamente interesante sería comenzar a practicar con modelos vivos. Conceptos que anteriormente se han estudiado en Bachillerato y resulta poco apropiado volverlos a repetir en la Universidad. Nuestro planteamiento parte de suponerlos aprendidos y empezar a instruir a los alumnos no tanto desde el manejo de técnicas sin importar lo que hagan como desde la idea de arte, dando un sentido a aquello que realizan además de practicar con la técnica.

Pintura I. Lenguajes y Materiales es una de las asignaturas de las que consideramos debe hacerse una revisión a su Guía Docente. Seguir realizando prácticas en torno al círculo cromático no es tarea del universitarios sino del niño de primaria ya que resultan conceptos excesivamente básicos sobre la teoría del color.

Dibujo Técnico también encuentra sus coincidencias entre lo impartido en Bachillerato y Grado, pero quizá el problema en este caso viene aún de más atrás, pues como ocurre con el círculo cromático, algunos sistemas de representación como el axonométrico ya se imparte en la E.S.O en asignaturas de Educación Plástica y Visual. En el caso del sistema diédrico también se dedica un extenso tiempo a ello en Bachiller, por eso creemos más acertado comenzar esta asignatura de Grado desde la perspectiva cónica aplicándola a modelos reales, algo que ya se viene haciendo pero a lo que se dedica poco tiempo.

Otra de las asignaturas que necesita considerar su plan docente es Teoría e Historia del Arte, en este caso los contenidos son exactamente los mismos. No puede ser que los alumnos estudien en Bachiller la historia del arte desde la prehistoria y al llegar a la universidad vuelvan a la prehistoria de nuevo. En la asignatura de Grado también se habla sobre teoría del arte y últimas tendencias artísticas, pero se hace al final de curso y en poco tiempo cuando lo interesante sería iniciar aquí la asignatura. 


\section{Conclusiones}

A lo largo de nuestro análisis hemos observado que existe un problema en nuestros planes de estudios puesto en práctica desde la llegada de los títulos de Grado. Con la esperanza de mejorar la calidad de nuestras enseñanzas hemos llevado a cabo esta investigación.

Consideramos que algunas asignaturas deben rehacer sus planes de estudios observando qué se ha estudiado en Bachillerato para no repetir los conceptos o no iniciar el curso desde niveles tan bajos. Quizá sería bueno hacer un repaso en las primera semana de curso pero no dedicar el primer año de Universidad a volver a enseñar lo que se enseña en Bachillerato ya que esto acarrea un retraso en los siguientes cursos y asignaturas. Si por ejemplo Teoría e Historia del Arte no impartiera exactamente lo mismo y aprovechara el tiempo en enseñar a los alumnos qué es el arte crecerían mucho más interiormente ya que a algunos alumnos de $4^{\circ}$ curso se les hace esa pregunta y aún no la saben responder.

Resulta curioso comprobar cómo el acceso a Bellas Artes no tiene ningún tipo de limitación, cualquier alumnos procedente de cualquier Bachillerato puede acceder a esta carrera. En cambio un alumno que haya estudiado Bachillerato Artístico encuentra unas limitaciones bastante grandes si finalmente no decidiera matricularse en el Grado de Bellas Artes. Así, para acceder a uno estudios científicos por ejemplo los alumnos deben haber realizado un Bachillerato de esta modalidad porque estas carreras establecen un punto de partida alto y considera aprendidos los contenidos de Bachillerato, cuando un alumno no alcanza el nivel esperado por norma general lo adquiere por su cuenta mediante estudio o clases particulares. Nos preguntamos por qué esto ocurre en gran parte de carreras y no en la nuestra.

\section{Bibliografía}

\subsection{Libros:}

AA.VV. (2004). Libro blanco sobre los estudios de Grado en Bellas Artes/ diseño / Restauración. ANECA

Agencia Ejecutiva en el Ámbito Educativo, Audiovisual y Cultural. (2010). La educación superior en Europa 2010 : el impacto del proceso de Bolonia. Madrid : Ministerio de Educación, Secretaría General Técnica.

ELIA Draft Report. (2010). ELIA Thematic Network Survey on the Implementation of Bologna in the Arts. Amsterdam

ELIA \& Hogeschool Gent. (2003). On the Move. Sharing Experience on the Bologna Process in the Arts. Amsterdam

Hidalgo, C., Caballero, F., Comunale, N., et al. (2005). Los estudios de Bellas Artes en el espacio Europeo de Educación Superior. Granada: Gráficas Alhambra. 
Ministerio de Educación, Subdirección General de Documentación y Publicaciones. (2010). Las Enseñanzas artísticas superiores en el Espacio Europeo de Educación Superior. Madrid: Grafo, S.A.

Scuola di Nuove Tecnologie Dell'Arte di Brera.(2010). Arte e Media. Formazione, ricerca produzione. Milán: Scalpendi Editore Normativa:

Ley orgánica 2/2006 de 3 de Mayo de Educación. (BOE: 4-5-2006)

Real Decreto 1614/2009, de 26 de octubre, por el que se establece la ordenación de las enseñanzas artísticas superiores reguladas por la Ley Orgánica 2/2006, de 3 de mayo, de Educación. (BOE:27-10-2009)

Orden de 5 de Agosto de 2008 por la que se desarrolla el currículo correspondiente a Bachillerato en Andalucía (BOJA: 26-8-2008)

\section{La autora}

Concepción Alonso (Almería 1984) es licenciada en Bellas Artes por la Universidad de Granada en 2008. Actualmente se encuentra realizando su Tesis Doctoral titulada "Análisis de los dibujos animados emitidos en Tv" bajo una beca de Formación de Personal Docente e Investigador otorgada por la Junta de Andalucía y por la que imparte clase de Dibujos Animados en la Facultad de Bellas Artes Alonso Cano de la misma universidad. 